\title{
Investor Behavior \& Fundamental Analysis: A Case of Karachi Stock Exchange Investor's
}

\author{
Nadeem Iqabl $^{1}$, Sajid Iqbal ${ }^{2}$ \\ ${ }^{1}$ Faculty of Management Sciences Ghazi University DG-Khan \\ ${ }^{2}$ Faculty of Management Sciences Indus International Institute DG-Khan \\ E-mail address: drnadeemiqabl1@gmail.com, sajid.edu@outlook.com
}

Keywords: Investor Behavior, Fundamental Analysis, Case of Karachi Stock, Exchange Investor's

\begin{abstract}
The current study hypothesized the investor behaviors with stock market fundamental analysis. Thus, the study used convinance and simple random sampling for data acquisition and study has used descriptive, correlation regression and combined effect $t$ tests to interpret the data. And have concluded that facets of investor behavior i-e overconfidence, optimism, involvement and risk behavior has significant relation with stock market fundamental analysis. Hence, study concluded its finding up to historic investigations.
\end{abstract}

\section{INTRODUCTION}

The behavior of corporate financial managers, stock market regulators and investors is found biased fundamentally and their decisions are prone as emotional decisions (Ramiah et al, 2014). Such behavior contains on overconfidence behavior, optimism behavior, involvement behavior and risk behavior (Iqbal \& Butt, 2015). And these behaviors are cognitive short-cuts (Baron, 2007).

Thus, Farsi et al, (2014) concluded that overconfidence behavior has significant relation with entrepreneurial decision in their study. Bao, (2014) has also concluded as adverse relation of such behavior with capacity generation. Iqbal \& Butt, (2015) concluded in their study such behavioral heuristics i-e overconfidence biases, optimism, being involved, loss aversion \& self serving behavior with respect to risk behavior have significant impact on working capital management in Pakistan context. Moreover, Chaffi \& Medhioub, (2014) concluded that such behavior has strong correlation with stock market performance.

However, such correlation with stock market is divided into two streams i-e fundamental oriented and technical oriented. And the analyses regarding these are pronounced as fundamental analysis and technical analyses. Thus, following the prospect theory by Denial Kahenamen \& Mark Tversky it is concluded that financial operators are humans and they have various emotions and cognitive traits psychologically. Therefore, financial markets including stock markets are affected mainly by such behaviors that have significant correlation with stock market fundamentals. Hence, fundamental analysis is selected to test its relation with behavioral biases originated from investor's behavior or investor cognition

The objective of study is to investigate the relationship of investor's behavior i-e overconfidence, optimism, involvement in stock market trading and risk attitude on investor's cognition. Moreover, the study is contextual and exploratory will reveal key implications for financial theorists, practitioners and market regulators.

Thus, the scheme of the study is that part one explains introduction, model \& hypothesis, part two explains methodology, part three results and part four concludes the study findings. So the study model is as follows, 


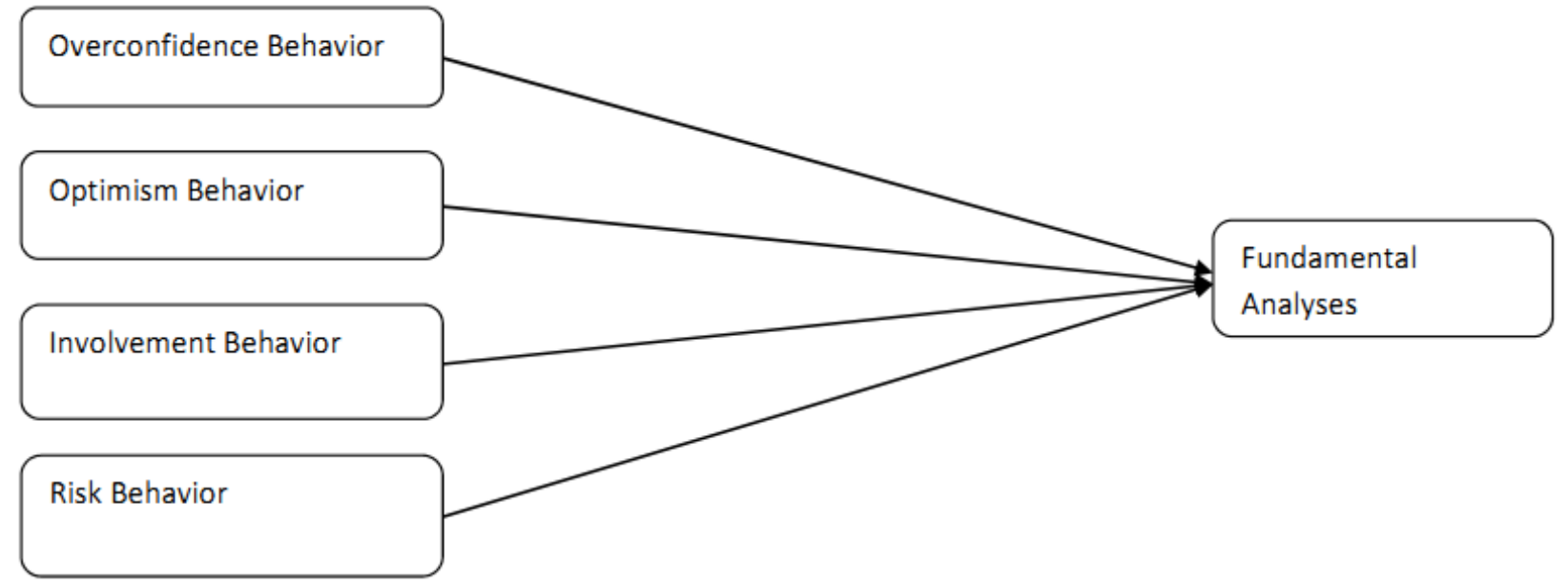

By following the prospect theory the hypothesis of the study are concluded as below,

H1: There is a significant negative relation of overconfidence behavior with stock market fundamental analysis

H2: There is significant positive relation of optimism behavior with stock market fundamental analysis

H3: There is a significant positive relation of involvement behavior with stock market fundamental analysis

H4: There is a significant negative relation of risk behavior with stock market fundamental analysis

\section{RESEARCH METHODOLOGY}

The current study explores the relationship of investor's behavior and investor cognition. The population of study contains on stock market investor of Pakistan. While, sample of the study contains on Islamabad and Lahore stock exchange investors. While, simple random technique is used to acquire the data. The data is acquired through scale. And questionnaire is distributed towards 520 individuals. Thus, the response is returned from 447 investors. So the study response rate is $85.9 \%$.

And regarding instrumentation study has used descriptive statistics, data reliability test, correlation analyses, regression analyses and combined sample t-test respectively. While, the variables are measured on seven point likert scale and scale is adopted from the study of (Iqbal \& Butt, 2015). And demographic variables are taken as control variables of the study because of their significance at every level in Pakistani context (Huang, \& Van De Vliert, 2003).

\section{RESULTS \& ANALYSIS}

Table 01

(Descriptive Analyses)

\begin{tabular}{ccc}
\hline Variables & Mean & Standard Deviation \\
\hline OCB & 6.77 & 24.67 \\
OPB & 2.31 & 3.97 \\
INB & 1.91 & 2.11 \\
RB & 4.57 & 7.82 \\
FA & 0.78 & 1.22 \\
\hline
\end{tabular}


The table 1 explains the results of descriptive analysis where mean of OCB are 6.77, OPB 2.31, INB 1.91, RB 4.57, FA 0.78. And the standard deviation of OCB is 24.57 , OPB as 3.97 , INB has $2.11, \mathrm{RB}$ has, 7.82 and $\mathrm{FA}$ is 1.22 respectively.

Table 02

(Reliability Analysis)

\begin{tabular}{cc}
\hline Variables & Cronbach's Alpha \\
\hline OCB & 0.0876 \\
OPB & 0.081 \\
INB & 0.73 \\
RB & 0.76 \\
FA & 0.667 \\
\hline
\end{tabular}

The table 02 elaborates the results of reliability of variables where OCB has 0.0876 , OPB has 0.081 , INB has $0.73, \mathrm{RB}$ is reliable at 0.76 and FA is reliable 0.667 that is less than standard criteria of reliability.

Table 03

(Correlation Analyses)

\begin{tabular}{ccccc}
\hline Variables & 1 & 2 & 3 & 4 \\
\hline OCB & 1 & & & \\
OPB & $0.23^{* *}$ & 1 & 1 & \\
INB & $0.97^{* *}$ & $1.21^{* *}$ & 1 & 1 \\
RB & $0.456^{* *}$ & $0.498^{* *}$ & $0.516^{* *}$ & 1 \\
\hline
\end{tabular}

The table 03 explains the results of correlation analysis as OCB correlated with OPB with $0.23 * *$ $\mathrm{p}<(0.01)$, OPB is correlated with INB with $0.97^{* *} \mathrm{p}<(0.01) \& 1.21^{* *} \mathrm{p}<(0.01)$. INB is correlated with $\mathrm{RB}$ as $0.456^{* *} \mathrm{p}<(0.01), 0.498^{* *} \mathrm{p}<(0.01)$ and $0.516^{* *} \mathrm{p}<(0.01)$ respectively.

Table 04

(Regression Analyses)

\begin{tabular}{cccc}
\hline Variable & B & t-stats & Probability \\
\hline C & 0.447 & 4.34 & 0.2379 \\
OCB & 0.7881 & 0.6787 & 0.000 \\
OPB & 0.5533 & 0.1357 & 0.000 \\
INB & 0.7135 & 0.4588 & 0.000 \\
RB & 0.8765 & 0.5242 & 0.000 \\
Adjusted R-Sq & 0.00247 & R-Square & 0.047 \\
\hline
\end{tabular}

Significance level at $<0.05$

The table four explains the results of correlation analysis where beta and $t$ stats values are plotted separately. Thus, OCB is found significant at significance level 0.01 , INB is also found significant, $\mathrm{OPB}$ is found significant with fundamental analysis of stock market and RB is also found significant with fundamental analyses at $\mathrm{p}<(0.01)$. Thus, the value of adjusted $r$-square is 0.00247 and r-square as 0.047 respectively. 
Table 06

(Combined Factor Analysis)

\begin{tabular}{cccc}
\hline Variable & Lower $\%$ & Upper \% & Significance \\
\hline OCB-FA & 0.43 & 0.67 & 0.000 \\
OPB-FA & 0.22 & 0.88 & 0.000 \\
INB-FA & 0.41 & 0.69 & 0.000 \\
RB-FA & 0.45 & 0.55 & 0.000 \\
\hline
\end{tabular}

The table six explains the results of combined factor analysis to confirm the results of regression analysis. Where, OCB, OPB, INB and RB are found significant with fundamental analysis. Moreover, the greater percentages of pairs are in higher side that also shows the matter of significance between pairs.

\section{CONCLUSION}

The current study explored the relationship of behavioral short cuts with stock market fundamental analysis and results have shown the significant correlation of overconfidence behavior, optimistic behavior, involvement behavior and risk behavior with sock market fundamental analysis. Thus, the study had shown its findings significant with historic investigations. Moreover, market practitioners have to develop principles for such fundamentals that may reduce such behavior incorporation in technical moves of stock markets. And it is recommended for future investigation to investigate such behaviors with stock market technical analysis.

\section{References}

[1] Ramiah et al. (2014). Behavioral finance approach to working capital management. European journal of Finance. (2014).

[2] Kahneman, D. \& Tversky. (1979). Prospect Theory: Decision making under Risk. Econometrica (pre-1986); Mar 1979; 47, 2.

[3] Farsi et al. (2014). Identifying the Main Factors Influencing the Formation of Overconfidence bias in entrepreneurs: A Qualitative Content Analyses Approach. International journal of academic research in business and social sciences, Vol. 04, No. 04.

[4] Bao, X, (2014). Research on Overconfidence in Decision-Making for the capacity if recovery of damaged power system. Hindawi Publishing Corporation. Vol 2014

[5] Chaffi, M. \& Mehdioub, I, (2014). Behavioral Finance: An empirical study of Tuniian Stock Market. International Journal of Economics 7 Financial Isues. Vol 04 No 03 (2014)

[6] Iqbal, S. \& Butt, S.A (2015). Impact of Behavioral Biases on Working Capital Management of Manufacturing Sector of Pakistan: A non-parametric investigation Approach. Journal of Poverty, Investment and Development. Vol 13 (2015) 